\title{
O Pibid e a dimensão afetiva: perspectivas do professor supervisor
}

\author{
Luiz Marcelo Darroz ${ }^{1}$ \\ Cleci T. Werner da Rosa ${ }^{2}$ \\ Nathalia Prediger ${ }^{3}$
}

\begin{abstract}
RESUMO
Este artigo apresenta os resultados de uma pesquisa qualitativa realizada junto a um conjunto de supervisores do subprojeto Pibid/Física da Universidade de Passo Fundo, na qual se buscou identificar indícios de mudança na relação afetiva do professor com sua profissão. A hipótese que originou este trabalho é que a realidade docente apresenta dificuldades e os professores se encontram desmotivados com a profissão. A coleta de dados se deu a partir de entrevistas semiestruturadas com seis professores de escolas públicas que, na época dessa coleta, possuíam bolsas de supervisão do subprojeto pesquisado. A análise dos dados guiou-se pela Análise Textual Discursiva (ATD), que teve como categorias a priori cinco dimensões relacionadas ao domínio afetivo. Como resultado, percebeu-se que o Pibid influencia na relação afetiva do professor com sua profissão, uma vez que as falas dos supervisores permitiram identificar componentes dessa dimensão, que se fazem presentes na mudança afetiva após entrarem no programa.
\end{abstract}

PALAVRAS-CHAVE: Pibid/Física. Domínio afetivo. Afetividade. Supervisores.

The Pibid and the affective dimension: perspectives of the supervisor teacher

\footnotetext{
${ }^{1}$ Doutor em Educação em Ciências, Universidade de Passo Fundo, Passo Fundo, RS, Brasil. E-mail: 1darroz@ upf.br.

${ }^{2}$ Doutora em Educação Científica e Tecnológica, Universidade de Passo Fundo, Passo Fundo, RS, Brasil. E-mail: cwerner@upf.br.

${ }^{3}$ Licenciada em Física, Universidade de Passo Fundo, Passo Fundo, RS, Brasil. E-mail: 145294@upf.br.
} 


\begin{abstract}
This article presents the results of a qualitative research performed along with a group of supervisors of the Institutional Scholarship Program for Teacher Initiation (Pibid)/Physics subproject of the University of Passo Fundo, RS, Brazil, which aimed to identify signs of change in the affective relation between teachers and their professions. The hypothesis that originated this work is that the teacher's reality presents difficulties and teachers find themselves unmotivated with the profession. Data was collected through semi-structured interviews with six public school teachers who, at the time of data collection, had scholarships for supervising the subproject investigated. Data was analyzed with the Discourse Textual Analysis (DTA), which had five dimensions related to the affective domain as a priori categories. As a result, it was observed that the Pibid has an influence on the affective relation between teachers and their professions, considering that the speech of supervisors allowed identifying components of this dimension, which are present in the affective change after entering the program.
\end{abstract}

KEYWORDS: Pibid/Physics. Affective domain. Affection. Supervisors.

\title{
Introdução
}

As dificuldades enfrentadas pelos professores no exercício do magistério têm promovido desmotivação, levando-os a questionar-se se devem permanecer na profissão. Lapo e Bueno (2003), ao realizarem um estudo sobre o desencanto e o abandono do magistério por professores da rede pública de São Paulo, revelam que os baixos salários, as precárias situações laborais, a insatisfação no trabalho e o desprestígio profissional estão entre os fatores que mais contribuem para que os professores optem pela mudança de profissão.

A questão salarial tem se apresentado como um dos problemas, contudo, como evidencia o estudo de Jesus (2004), há outras questões que 
afetam a autoestima e, por vezes, levam ao abandono do magistério, como o comportamento e o desinteresse dos estudantes. Dentre essas questões está o que Charlot (2008, p. 17) denomina de "contradições que decorrem da contemporaneidade econômica, social e cultural”. Tais contradições, no entendimento do autor, estão relacionadas ao fato de que, ao mesmo tempo em que o professor deve ensinar a todos os alunos, muitos deles não querem aprender ou "vão à escola para tirar boas notas e passar de ano" (CHARLOT, 2008, p. 23).

Essa relação contraditória com a própria finalidade da escola na educação é causadora de desmotivação entre os professores, uma vez que a sua função acaba sendo apenas a de transmitir conhecimentos e aprovar os alunos. Ainda, pautando-se na reflexão proporcionada por Charlot (2008), tem-se que os professores brasileiros, a exemplo da maioria dos docentes no mundo inteiro, são basicamente tradicionais. E esse modo de ser se justifica "porque a escola é organizada para tais práticas e, ainda que seja indiretamente, impõe-nas" (CHARLOT, 2008, p. 24), ou, então, porque muitas vezes os docentes de hoje utilizam os mesmos métodos que eram utilizados pelos seus professores tempos atrás.

$\mathrm{Na}$ busca por soluções, a literatura e especialmente as pesquisas na área de Educação mostram que as práticas de natureza construtivista poderiam ser uma alternativa para ressignificar e mobilizar a ação pedagógica dos professores. Contudo, Charlot (2008, p. 25) chama a atenção para o fato de que "faz-se claro que a questão fundamental não é saber se a professora é 'tradicional' ou 'construtivista', mas como ela resolve duas tensões inerentes ao ato de ensino e ao de educar".

Essas tensões passam pela identificação com o papel de ser professor, que envolve sentimentos e emoções associados a dimensões habitualmente desconsideradas nas pesquisas em Educação. Segundo Lapo e Bueno (2003, p. 84), o professor apresenta um sentimento de acomodação que é entendido como "o distanciamento da atividade docente mediante condutas de indiferença a tudo que ocorre no ambiente escolar, ou de um tipo de inércia, 
no sentido de buscar inovações e melhorias no ensino, um não envolvimento com o trabalho e com os problemas cotidianos da escola".

Esse estado inercial em que muitos professores se encontram imersos e que pode desestabilizá-los é o que se pretende investigar nesta pesquisa. De forma mais específica, o estudo pauta-se na investigação da potencialidade da formação continuada como a ofertada pelo Programa Institucional de Bolsa de Iniciação à Docência (Pibid) para mobilizar os professores e promover um sentimento positivo em relação à profissão. Tal sentimento é traduzido por questões de ordem afetiva como autoestima, confiança em si mesmo, motivação e outras.

O Pibid é um programa do governo federal que concede bolsas a licenciandos com o propósito de promover a sua inserção no cotidiano das escolas públicas durante a formação acadêmica, para que desenvolvam atividades didático-metodológicas com a orientação de um docente da licenciatura e a supervisão de um professor da escola de educação básica da rede pública de ensino. Os pibidianos ${ }^{4}$, juntamente com os supervisores, organizam, planejam, elaboram e/ou escolhem as atividades que irão aplicar na escola pública (DARROZ, 2016). Conforme Darroz (2016), o programa proporciona oportunidades de criação e participação de atividades docentes de caráter inovador e interdisciplinar, com a articulação entre a teoria e a prática, necessárias à formação dos docentes, elevando a qualidade das ações acadêmicas nos cursos de licenciatura.

Essa iniciativa, além de inserir licenciandos no contexto escolar, elevando assim a qualidade da formação inicial de professores nos cursos de licenciatura e promovendo a integração entre educação superior e educação básica, oportuniza o aperfeiçoamento e a valorização da formação de professores para a educação básica e do próprio magistério. Acrescenta-se a isso o incentivo dado às escolas públicas de educação básica, mobilizando seus professores como coformadores dos futuros docentes e tornando-os protagonistas nos processos de formação inicial e continuada (BRASIL).

\footnotetext{
${ }^{4}$ Forma como são conhecidos os bolsistas de iniciação à docência do Pibid.
} 
Os supervisores, além de auxiliar os pibidianos na sua formação e na oportunidade de vivenciar o ambiente escolar, devem manter a escola informada acerca das ações e práticas a serem aplicadas no contexto escolar pelo Pibid, elaborando relatórios das atividades desenvolvidas pelos bolsistas, participando de eventos da área na universidade e sendo o vínculo entre esta e a escola (DARROZ; WANNMACHER, 2016).

Frente a esse contexto, muitas vezes marcado pela desmotivação e pelo desinteresse dos docentes na execução de suas atividades profissionais, e à oportunidade de formação continuada proporcionada pelo Pibid, surge a seguinte indagação: de que forma o Pibid mobiliza a renovação da relação afetiva do professor com a sua profissão? $\mathrm{Na}$ tentativa de responder a essa pergunta, realizou-se uma investigação voltada a identificar as contribuições do programa para a renovação do sentimento de ser professor, evidenciando a importância desse sentimento tanto para o aprimoramento das práticas pedagógicas quanto para a evolução pessoal relativa à profissão.

Assim, este artigo se estrutura da seguinte forma: na próxima seção, é apresentada uma reflexão sobre o domínio afetivo, em especial as categorias atribuição, atitude, emoção, confiança em si mesmo e motivação; na sequência, descreve-se a metodologia da pesquisa desenvolvida; a seguir, divulgam-se os resultados alcançados; e no encerramento, expõem-se as considerações finais.

\section{Fundamentação teórica}

Cada vez mais, dentro do meio educacional, tem se dado uma maior abrangência aos aspectos emocionais e afetivos nos processos cognitivos, embora seja recente a consideração da dimensão afetiva como elemento integrante de atividades que envolvem a razão. Até o século XX, acreditavase que a Ciência, para alcançar o conhecimento verdadeiro, deveria ser racional e livre de sentimentos (PINHEIRO, 2003). 
Além disso, esses elementos não são analisados como mediadores das relações humanas e educacionais. Com efeito, Santos (1996, p. 136) salienta que:

A dimensão afetiva como um mecanismo de construção (ou desconstrução) de conhecimentos entre os sujeitos sociais não é abordada. Assim, os afetos e desafetos se manifestam na aproximação com o conhecimento científico, mas não é discutido como a aproximação do conhecimento científico causa afetos e desafetos, ou como eles surgem durante o processo de escolarização.

$\mathrm{Na}$ literatura especializada, existe uma imensa divergência sobre a conceituação da afetividade e seus fenômenos, e muitas vezes os termos "afeto", "emoção" e "sentimento" são empregados como sinônimos (PINHEIRO, 2003). Essa divergência pode ser a causa, conforme Santos (1996) e Pinheiro (2003), do reduzido número de estudos envolvendo o ensino de Ciências e a afetividade.

O fato de a afetividade ser vista como uma área pouco objetiva, que a princípio comprometeria a neutralidade do ensino, talvez seja um dos motivos de receio de se apresentar questões relacionando esses dois campos. Na concepção de Rosa (2014), uma das razões de os aspectos afetivos não serem considerados no processo de ensino-aprendizagem pode ser a dificuldade de conceituar e avaliar o comportamento afetivo. No entanto, para Pinheiro (2003), a preparação de intervenções baseadas no domínio afetivo pode se concretizar de diferentes maneiras (intervenções individuais ou em grupo, intervenções ligadas à dimensão afetiva integradas direta ou indiretamente ao conteúdo teórico, etc.), de acordo com o tipo de estudante, com as características do professor ou com o conteúdo teórico a ser ensinado, e, consequentemente, auxiliar no processo de aprendizagem. 
Nessa direção, a definição de afeto e domínio afetivo é proposta por Mcleod (1989, p. 245 apud FERREIRA, 2012, p. 42) como uma "extensa categoria de sentimentos e humor que são geralmente considerados como algo diferente da pura cognição". O marco inicial das pesquisas em ensino que abordam a dimensão afetiva consiste no trabalho de Martin e Briggs (1986 apud LAFORTUNE; SAINT-PIERRE, 1996). Nele, os autores desenvolveram uma terminologia e conceituaram o domínio afetivo, permitindo maior compreensão de cada uma das categorias que o compõem, que são "as atitudes e os valores, o comportamento moral e ético, o desenvolvimento pessoal, as emoções (entre as quais, a ansiedade) e os sentimentos, o desenvolvimento social, a motivação e, finalmente, a atribuição" (MARTIN; BRIGGS, 1986 apud LAFORTUNE; SAINT-PIERRE, 1996, p. 25).

A dimensão afetiva abordada neste texto se dá a partir dos estudos de Lafortune e Saint-Pierre (1996), que apresentam algumas definições relativas a ela. $\mathrm{Na}$ sua investigação, as autoras propõem um material didático que considera as dimensões afetiva e metacognitiva da aprendizagem, apontando, dessa forma, que os educadores perdem uma excelente oportunidade de evitar os constantes fracassos dos estudantes por não explorarem objetivos do domínio afetivo (PINHEIRO, 2003).

Lafortune e Saint-Pierre (1996) se utilizam das componentes do domínio afetivo conceituadas por Martin e Briggs (1986), nas quais destacam os termos atitude, emoção, motivação e atribuição para uma definição mais geral. A essas, acrescentam a componente confiança em si mesmo, considerando a importância desse aspecto no processo de aprendizagem. Assim, na continuidade, são detalhadas todas as componentes mencionadas, que servirão de base para a análise dos dados coletados na presente pesquisa.

As atitudes, segundo Legendre (1993), estão relacionadas a "um estado de espírito" que o sujeito adquire sobre si e/ou de algum elemento externo, como uma pessoa ou um evento, que incentiva a forma de estar ou de agir 
favorável ou desfavorável (LAFORTUNE; SAINT-PIERRE, 1996). Isto é, trata-se de posturas adotadas diante de uma determinada situação. "Essas ideias influenciam o modo como vemos as coisas, o modo de ser e o comportamento" (PINHEIRO, 2003, p. 58).

De acordo com Lafortune (1992 apud LAFORTUNE; SAINT-PIERRE, 1996), as atitudes do professor sobre o que ele pensa a respeito de sua disciplina, ou da capacidade de seus alunos, leva-o a buscar meios e métodos que os ajudem a eliminar dificuldades, a estarem atentos ao processo, identificando mais facilmente os erros de raciocínio. Assim, esse professor busca entender as razões dessas falhas, sobretudo se os alunos tiveram empenho para realizar as atividades (LAFORTUNE, 1992 apud LAFORTUNE; SAINT-PIERRE, 1996, p. 32).

“As atitudes são aprendidas e adquiridas pela experiência, por isso elas devem ser trabalhadas no início da aprendizagem" (WLODKOWSKI, 1985 apud PINHEIRO, 2003, p. 58), pois podem interferir na concepção que os estudantes formarão a respeito da disciplina ou de si mesmos. Além disso, Pinheiro (2003) afirma que um dos motivos de insegurança dos professores está ligado a uma atitude explícita, em que a definição de objetivos relacionados a esse elemento poderia implicar a doutrinação, visto que "as atitudes e as crenças do professor, explicitadas em suas falas e posturas adotadas em sala de aula, exercem influência sobre as metas e motivações, crenças e atitudes dos alunos" (FERREIRA, 2012, p. 45).

Por seu turno, a atribuição consiste na interpretação que o sujeito faz das causas de um evento, podendo ser, conforme Lafortune e Saint-Pierre (1996), interna, se depender da pessoa envolvida, e externa se não depender. A atribuição interna ocorre quando o indivíduo interpreta seu comportamento, ou de outra pessoa, considerando a capacidade pessoal, o esforço, a dedicação. Já a atribuição externa é, por exemplo, associada ao nível de dificuldade envolvido na atividade a ser realizada (PINHEIRO, 2003). A atribuição pode determinar a atitude futura de uma pessoa diante de uma situação semelhante, pois “esta percepção, ideia, preconceito sobre si 
ou sobre seu entorno, influencia o modo de ser e o comportamento" (PINHEIRO, 2003, p. 58).

Quando um professor atribui o bom desempenho de seus alunos unicamente ao talento que eles têm, ou seja, não considera que esse talento ou mesmo o interesse da turma depende dele próprio, dificilmente trará metodologias diferenciadas para tentar superar as dificuldades de aprendizagem (LAFORTUNE; SAINT-PIERRE, 1996; PINHEIRO, 2003). Em contrapartida, "um aluno que atribui um bom desempenho escolar exclusivamente ao comportamento do professor dificilmente se sentirá capaz de realizar uma tarefa por conta própria" (LAFORTUNE; SAINT- PIERRE, 1998 apud PINHEIRO, 2003, p. 58).

Lafortune e Saint-Pierre (1996) utilizam a definição proposta por Sillamy (1980) e Martin e Briggs (1986) para estabelecer o conceito da categoria emoção. No entendimento das autoras, as emoções são uma reação afetiva que se manifesta de diferentes maneiras, como medo, raiva, alegria, tristeza, desgosto, angústia, prazer, ansiedade, as quais podem ser identificadas diante de algumas atividades de aprendizagem.

Nas palavras de Reeve (2015, p. 191),

as emoções, fenômenos expressivos e propositivos, de curta duração, que envolvem estados de sentimento e ativação e nos auxiliam na adaptação às oportunidades e aos desafios que enfrentamos durante eventos importantes da vida, [...] são sistemas sincronizados que coordenam sentimento, ativação, propósito e expressão.

Santos (2001), ao analisar a complexidade das dinâmicas das interações nas aulas de Química, investiga os aspectos emocionais e conclui que as emoções e os sentimentos desempenham um papel importante na construção de significados, porque estão relacionados aos impulsos, aos interesses e às motivações dos alunos e do professor no trabalho com o conhecimento. A autora cita que, no processo de ensino e aprendizagem, as 
emoções se dão por estados de prazer e dor, paixão por aprender, ansiedade e medo diante de uma disciplina. "Alguns destes se vinculam mais diretamente com o ensino, pois estão relacionados aos processos de comunicação necessários à aprendizagem e dependem do comportamento do professor" (PINHEIRO, 2003, p. 56).

Damásio (1996) afirma que as emoções têm a função de comunicar significados a terceiros e podem cumprir um papel de orientação cognitiva. Isso porque algumas delas são desencadeadas após um processo mental voluntário de avaliação da situação, e não por algum instinto (PINHEIRO, 2003). O autor ainda discute três níveis de emoção: primário, secundário e de fundo. O primeiro nível é considerado como de emoções básicas, reações em situações emergenciais ou sensações de emoção que permitem antecipar ações, fazer generalizações. É a manifestação do que o indivíduo sente diante de uma situação ou objeto e compreende os sentimentos de alegria, tristeza, medo, raiva, surpresa e repugnância (MARTIN; BRIGGS, 1986 apud DAMÁSIO, 1996, 2000; LAFORTUNE; SAINT-PIERRE, 1996; REEVE, 2015).

As emoções secundárias surgem, também, com os primeiros sentimentos, assim que se inicia a formação de relações entre categorias de objetos e/ou situações e emoções primárias. Embaraço, ciúme, culpa, orgulho são emoções desse tipo (DAMÁSIO, 1996, 2000). As reações dependem de experiências pessoais semelhantes vividas anteriormente, apresentando características próprias a cada pessoa, e podem ser percebidas por mudanças no estado do corpo, como, por exemplo, alteração cardíaca e contrações musculares (PINHEIRO, 2003).

Por fim, as emoções de fundo são reações internas, manifestadas na maior parte do tempo e nem sempre associadas a grandes estados de alteração no organismo. Dessas, surgem os sentimentos de fundo, dos quais se destacam calma, fadiga, energia, excitação, bem-estar, mal-estar, tensão, descontração, arrebatamento, desinteresse, estabilidade, instabilidade, equilíbrio, desequilíbrio, harmonia e discórdia (DAMÁSIO, 1996). 
No ensino, as manifestações de emoções do professor, tais como alegria, decepção ou raiva, resultam no modo como os estudantes participam e/ou no seu desempenho nas atividades propostas (LAFORTUNE; SAINT-PIERRE, 1996). Assim, quando o professor se apresenta animado, a tendência é que os estudantes se envolvam mais nas atividades propostas (PINHEIRO, 2003). Além disso, Lafortune e Saint-Pierre (1996, p. 34) afirmam que "o professor que experimenta mal-estar relativamente à utilização de atividades, incidindo sobre a dimensão afetiva no seu curso, utiliza as atividades com prudência, sem grande conviç̧ão; ele é facilmente tentado a modificar alguns dos seus elementos". Assim, uma vez que o medo é a emoção provocada diante de uma ameaça, o professor, com receio de utilizar tais metodologias, as evita o tanto quanto possível.

Dessa forma, as emoções estão intensamente ligadas às próximas categorias, a confiança em si mesmo e a motivação, sendo um importante componente no processo de ensino-aprendizagem, tanto na atuação do aluno como na atuação do professor (LAFORTUNE; SAINT-PIERRE, 1996; DAMÁSIO, 2000; PINHEIRO, 2003).

"Quem se conhece melhor (reconhece seus avanços e dificuldades), em relação as suas capacidades, consegue se sair melhor nas atividades propostas, mesmo não sendo melhor que os outros" (PINHEIRO, 2003, p. 60). A confiança em si mesmo é um conceito relacionado à autoestima, em que o indivíduo cria uma representação de si próprio acerca da sua capacidade de executar uma tarefa, ou quando compara suas capacidades com as dos outros. Ou seja, ela pode ser entendida como uma crença sobre a própria competência e capacidade para alcançar determinado objetivo (FERREIRA, 2012). Lafortune e Saint-Pierre (1996) afirmam que uma experiência de sucesso pode ajudar a sustentar ou aumentar a autoconfiança, ao passo que "a falta de confiança pode desencorajar a pessoa diante da mínima dificuldade" (PINHEIRO, 2003, p. 59).

Assim, a confiança em si mesmo interfere no trabalho do professor. Pinheiro (2003) refere que, se um professor apresenta habilidade em 
ministrar aulas expositivas, é possível que tenha preferência por esse método e acabe utilizando-o mais que outros, pois se sente mais confiante. Por outro lado, se ele se sente pouco seguro em relação a algum conteúdo ou metodologia, possivelmente tende a evitá-los, consciente de suas capacidades e limitações na execução de tarefas (BARROS; LABURÚ, 2017). Diante disso, a confiança em si mesmo interfere no planejamento das atividades que serão oferecidas, afetando também o desenvolvimento acadêmico dos estudantes e o julgamento que farão sobre sua própria capacidade (FERREIRA, 2012). Que fique claro que não se trata de possuir capacidades, mas de acreditar que as possui, como resultante da interação das crenças, atitudes e ações do professor. E isso explica por que muitos professores se sentem motivados e confiantes em algumas situações e em outras, não (BARROS; LABURÚ, 2017).

No ensino de Ciências, Pinheiro (2003) apresenta como exemplo as atividades experimentais. Apesar de concordarem que a experimentação é importante, o autor adverte que na maioria das vezes os docentes dão "n" motivos para não as desenvolver, sendo um deles a falta de confiança em aplicá-las no ensino.

A motivação talvez seja a categoria da dimensão afetiva mais conhecida e utilizada pelos professores e pesquisadores do processo de ensino-aprendizagem (PINHEIRO, 2003). Na concepção de Legendre (1993 apud LAFORTUNE; SAINT-PIERRE, 1996), a motivação consiste em um conjunto de aspirações que uma pessoa possui para atingir um objetivo ou cumprir uma atividade, correspondente a suas necessidades ou seus interesses. A motivação é o elemento da afetividade que mais pode ser explorado, pois geralmente influencia o modo de agir da pessoa diante de determinadas situações. As pesquisas sobre motivação no meio educacional têm crescido nos últimos anos e recebido diversos enfoques teóricos, o que se deve, segundo Ferreira (2012), à sua complexidade e à preocupação de entender os aspectos relacionados a ela dentro do contexto escolar. 
Lafortune e Saint-Pierre (1996) salientam que a motivação pode ser separada em intrínseca e extrínseca. A motivação intrínseca depende da própria pessoa, mas também pode ser estimulada por fatores externos, reconhecida pelo interesse e pela satisfação na atividade em si. Provoca, em longo prazo, resultados mais profundos e mais duradouros. Ela ocorre quando a pessoa faz algo de que gosta, quando sente satisfação ao realizar uma atividade, quando vê significado na atividade por ela mesma, e não por algo que lhe servirá no futuro (LAFORTUNE; SAINT-PIERRE, 1996; PINHEIRO, 2003). Por sua vez, a motivação extrínseca é relacionada a ações realizadas em resposta a fatores externos ao sujeito, que visa objetivos desejáveis, produzindo resultados imediatos mais impressionantes do que a motivação intrínseca, porque envolve a busca por recompensas (LAFORTUNE; SAINT-PIERRE, 1996).

Lafortune e Saint-Pierre (1996) ressaltam que um professor motivado é capaz de encontrar meios pedagógicos que estimulem os alunos, ajudando-os a suprimir as dificuldades e desenvolver atitudes positivas durante o processo de ensino-aprendizagem, ou seja, é capaz de torná-los igualmente motivados diante das atividades escolares. Ao contrário, a falta de motivação, tanto do professor quanto dos estudantes, gera apenas desinteresse perante as atividades de sala de aula. Assim, de acordo com as autoras, sem motivação não ocorre a aprendizagem, isto é, a motivação é um aspecto central quando se trata de aprender.

Dentro dos objetivos do Pibid, os supervisores são os sujeitos que acompanham diretamente a ação dos acadêmicos no ambiente escolar, auxiliando no planejamento das ações, na elaboração das propostas, na discussão teórica, entre outras ações que subsidiam a implementação das atividades relativas ao programa, e dessa forma acabam participando de uma formação continuada. A hipótese é que, ao participarem desse espaço de formação, os aspectos emocionais e afetivos sejam fortalecidos. É no sentido de evidenciar esses aspectos que o presente trabalho se orienta. Para 
tanto, na próxima seção, é descrita a metodologia utilizada nesta investigação.

\section{A pesquisa}

Para o desenvolvimento da pesquisa aqui apresentada, projetou-se um estudo de natureza qualitativa, nos termos anunciados por Gil (1994), que considera a existência de uma relação entre o mundo e o sujeito que não pode ser traduzida em números; ou seja, a pesquisa é descritiva, e o pesquisador tende a analisar seus dados indutivamente. Além da abordagem qualitativa, elaborou-se um estudo exploratório que, conforme Gil (2002), tem como objetivo proporcionar maior familiaridade com o problema, com vistas a torná-lo mais explícito, aprimorando ideias, e, por ser bastante flexível, possibilita a consideração dos mais variados aspectos relativos ao fato estudado.

Para a obtenção dos dados que compuseram o corpus, realizaram-se entrevistas semiestruturadas com professores que ministram aulas de Física em escolas públicas do Rio Grande do Sul e que participaram, até então, do Pibid - subprojeto Física desenvolvido na Universidade de Passo Fundo (UPF), na condição de bolsistas supervisores. O subprojeto Física da UPF foi implementado no ano de 2010, e até o momento da coleta de dados oito professores da educação básica haviam feito parte do programa na condição de bolsistas supervisores. Desse grupo, seis aceitaram participar do estudo, e quatro permanecem atuando como bolsistas do programa. Esses professores ministram aulas de Física na educação básica há um período que corresponde entre cinco e quarenta anos e, em média, participam do programa há cinco anos.

A opção pela entrevista semiestruturada deve-se ao fato de que esse instrumento se mostra flexível e possibilita uma grande interlocução do entrevistador com o entrevistado (LUDKE; ANDRÉ, 1986). As entrevistas 
foram orientadas por um conjunto de questões ${ }^{5}$, mas, quando necessário, foram feitas outras perguntas, visando obter informações adicionais e esclarecimentos a respeito do objeto de pesquisa. A fim de evitar a identificação dos entrevistados, ao longo do texto, todos são mencionados no gênero masculino e nominados por E1 a E6.

As entrevistas foram transcritas e submetidas aos procedimentos da Análise Textual Discursiva (ATD), um instrumento analítico que transita entre duas formas consagradas de análise na pesquisa qualitativa, a análise de conteúdo e a análise de discurso (MORAES; GALIAZZI, 2006), em que o material de análise é denominado de corpus. Esse material pode ser produzido especificamente para a pesquisa, como é o caso das entrevistas com os supervisores, ou pode se referir a materiais já existentes na literatura (MORAES; GALIAZZI, 2011). Moraes e Galiazzi (2006) descrevem que a análise se desloca do empírico para a abstração teórica, que só pode ser alcançada se o pesquisador fizer um movimento intenso de interpretação e produção de argumentos. Esse processo todo cria espaços de reconstrução, envolvendo-se nesses diversificados elementos, especialmente a compreensão da produção de significados sobre os fenômenos investigados e a transformação do pesquisador.

A ATD compõe-se por três etapas: unitarização, categorização e comunicação. Na unitarização, o texto analisado é desmontado/fragmentado em unidades de significado. A unitarização ganha sentido dentro da pesquisa quando encaminha o texto para a categorização, em que as unidades de significado são agrupadas de acordo com compreensões

\footnotetext{
${ }^{5}$ Por que escolheu a profissão de professor? Por que optou pela Física?

Como é/foi sua participação no programa? Quais as principais atividades que desenvolveu?

Como era o planejamento de suas aulas antes da participação no Pibid? E como é agora junto com acadêmicos?

Quais os métodos que utilizava em suas aulas? E depois de ingressar no Pibid, ainda leva as mesmas coisas?

O trabalho com os pibidianos mudou sua postura em sala de aula? Como?

Como você trabalhava com os estudantes com dificuldades? E o que você acha que pode ser a causa dessas dificuldades? O Pibid te ajudou a contornar essas dificuldades? De que forma?

E com os alunos que demonstravam interesse e facilidade, como era o trabalho? Como se sentia em relação a isso? Como o programa ajuda nesse despertar de interesses?

Já pensou em desistir da profissão? O Pibid ajudou a mudar essa ideia? Por quê?

Quais as principais aprendizagens que teve durante sua participação no programa?

Qual é seu papel em relação aos pibidianos?

O que o Pibid representa para você e para sua profissão?
} 
semelhantes. Logo, a categorização apresenta uma função classificatória. As categorias constituem elementos de organização do novo texto que se pretende escrever, ou seja, é a partir delas que se descreverá e interpretará o material analisado (MORAES, 2003; MORAES; GALIAZZI, 2011).

De acordo com os pressupostos da ATD, as categorias podem ter um caráter amplo (MORAES, 2003). Nesse tipo de análise, admite-se a utilização de três tipos de categorias, a saber: as categorias a priori, as emergentes e as mistas. As categorias a priori são as já existentes na literatura e às quais o pesquisador recorre para enquadrar os dados. As categorias emergentes são aquelas que surgem a partir da análise do corpus, isto é, o pesquisador as constrói a partir da análise dos dados recolhidos durante a pesquisa. As mistas, como o próprio nome indica, mesclam as duas categorias anteriormente mencionadas (MORAES, 2003).

As categorias apresentadas neste texto são a priori, uma vez que se reuniram os fragmentos oriundos da desconstrução do corpus de acordo com as características enunciadas por Lafortune e Saint-Pierre (1996) em seus estudos sobre a dimensão afetiva. Isto é, observaram-se os fragmentos das falas e procurou-se verificar as semelhanças entre eles e as categorias.

A última etapa da ATD corresponde à comunicação, em que são construídos os metatextos interpretativos e/ou descritivos. É nessa etapa que o pesquisador realiza reflexões, anuncia pontos de vista devidamente fundamentados e opõe-se a outros, expressa sua voz no texto, além de possibilitar um novo modo de compreender as informações submetidas à análise (MORAES; GALIAZZI, 2011). Cabe destacar que, na ATD, o pesquisador assume-se como autor das interpretações que constrói, o que contribui para enfatizar a ideia de não neutralidade teórica na pesquisa realizada. Em linhas gerais, a ATD é um exercício de produzir e expressar sentidos (MORAES; GALIAZZI, 2011).

De acordo com a descrição acima, a pesquisa aqui apresentada desenvolveu-se mediante a leitura, a desconstrução e a unitarização dos dados recolhidos pelas entrevistas, bem como por meio da categorização das 
falas dos supervisores segundo a afetividade vinculada ao sentimento de ser professor, proporcionando as interpretações e as conclusões registradas na próxima seção.

\section{Apresentação e discussão dos resultados}

A análise dos dados obtidos evidencia, na fala dos pesquisados, a presença dos elementos que contemplam as cinco componentes do domínio afetivo abordadas neste estudo: atitude, atribuição, emoção, confiança em si mesmo e motivação. Apesar de tais categorias terem sido elaboradas para a aprendizagem, a sua utilização nesta investigação deve-se à compreensão de que elas apresentam potencialidades para a análise da identificação do sentimento de ser professor e da renovação na prática docente dos sujeitos pesquisados.

Em todas as entrevistas realizadas, foi possível observar características que demonstram a influência do Pibid/Física na relação afetiva do supervisor com a profissão docente. Na sequência, apresentam-se e comentam-se fragmentos dos depoimentos que revelam a identificação mencionada.

\section{Atitude}

O primeiro elemento buscado foi a atitude do profissional, que, em âmbito de ensino, é relacionada às posturas que o professor adota ao deparar-se com situações específicas. Ou seja, o educador está atento às dificuldades e procura meios para exprimi-las, principalmente quando percebe o esforço dos estudantes (LAFORTUNE; SAINT-PIERRE, 1996). Tais características foram percebidas no seguinte trecho da fala de E1: "Olha, a gente sempre faz uma reflexão [...] o que que a gente está fazendo? $O$ que que tá faltando? [...]. Nós temos que trabalhar nos recursos que nós temos [...] então eu sempre procurava refletir e, após essa reflexão, quando for 
preciso, buscar outras formas de ensinar". Essa fala é corroborada pelos demais supervisores, como se pode perceber nos trechos das entrevistas transcritas no Quadro 1:

Quadro 1 - Trechos das entrevistas que demonstram elementos da categoria atitude presentes na fala dos supervisores pesquisados

Eu tentava, eu sempre tentei, mas é dificil porque a gente tem muitas turmas, mas sempre tentei me aproximar, conversar, uma coisa que eu acho importante é que, se o aluno não gosta, "ai, eu não gosto, detesto". Muitos diziam que me detestavam. Depois de um tempo que o que que tu tem que ter é o manejo [...], o manejo com o aluno, bater de frente não resolve, tu tem que tentar, tem que conversar, procurar por outros meios, porque o aluno tem que criar uma afetividade contigo, pra gostar também da matéria. Estar no Pibid me fez perceber o quanto importante é ir atrás do aluno, de tentar trazer ele para a matéria (E3).

A forma como [a Física no ensino fundamental] é apresentada pra eles, é como se ela fosse muito difícil, e muito cálculo, então quando eles chegavam no primeiro ano do ensino médio, que que é, a Física é difícil. Então, uma das coisas que foi tentado quebrar no primeiro ano que eu tava no Pibid é quebrar essa, como que eu posso dizer, quebrar esse conceito que eles têm de que a Fisica era difícil (E4).

Eu sempre trabalhei com os alunos com dificuldade [...]. [Essa dificuldade] de um modo geral é a falta de atenção, distração. Porque o mesmo aluno que disse que não entendeu nada, e eu fico brava, porque alguma coisa tem que ter entendido. Dai eu digo pra ele ir me procurar no recreio, porque no programa buscamos muito perceber as dificuldades de cada um e tentar saná-las [...], vamos a uma sala pra atendimento individual aos alunos, e explico pra ele, ele entende. Então não é um aluno que tem maiores dificuldades, mas se é um aluno que tem maiores dificuldades, por outros motivos, ele dá trabalho, mas, como conversávamos num encontro do Pibid aqui na universidade, todos têm direito a aprender (E5).

Fonte: dados da pesquisa, 2017.

Quando questionados sobre a importância do programa nessa alteração de atitude, os professores revelaram que trabalhar com professores em formação em idade próxima à dos estudantes do ensino médio contribuiu muito no desenvolvimento das aulas, pois eles compartilham gírias que muitas vezes permitem uma aproximação maior com os alunos da escola. Ainda, segundo os pesquisados, a possibilidade de trabalhar em grupos tornou as aulas diferenciadas. Isto é, na concepção dos supervisores, planejar, ministrar, refletir em conjunto - supervisor e bolsista de iniciação 
- oportuniza que as aulas sejam mais contextualizadas e que as dificuldades sejam detectadas mais facilmente, elementos que podem ser percebidos nos trechos das entrevistas contidos no Quadro 2.

Quadro 2 - Trechos das entrevistas que demonstram alteração de atitude dos supervisores pesquisados ao participar do Pibid/Física

Bom, o sistema melhorou um pouco, porque dai tem os acadêmicos, que eles pensam mais como os alunos que estão lá na educação básica, por se tratar de terceiro ano, então acho que eles estão pensando mais em exercícios que estão mais ligados ao seu cotidiano. Então nós estamos até fugindo do livro didático e trazendo mais exercicios que, assim, estejam no dia a dia, estejam mais frequentes no seu dia a dia. E eu acredito que essas duas turmas que o Pibid engloba, que são duas turmas do terceiro ano, são as que mais tiveram desempenho melhor, depois que o Pibid entrou na escola. Então eles têm uma relação melhor com a Física, até eu vejo que eles estão mais motivados, talvez com a presença e apoio dos acadêmicos, talvez por essa diversidade de atividades [...] que não é mais só a parte mecânica. Eu acho que houve evolução significativa (E1).

Antes era mais difícil de detectar que aluno tinha dificuldade, porque na maioria das vezes eles não nos chamam [...], eles ficam quietos, e aparentemente todo mundo entendeu. Agora com os pibidianos é mais fácil, a gente vai passando, a gente tem um contato maior com os alunos, por ter mais pessoas pra ajudar. Ai a gente tenta sentar com aquele aluno, mostrar de uma maneira diferente. Às vezes eu explico, depois vai o pibidiano e explica do jeito dele (E2).

Com o Pibid tinha mais apoio, sim. Normalmente a gente fazia umas aulas diferenciadas, levava um video, fazia um lançamento de foguetes, sempre tentava concretizar mais e mostrar o lado prático relacionado com o dia a dia (E6).

Fonte: dados da pesquisa, 2017.

Os dados encontrados indicam que participar do Pibid/Física auxiliou na alteração das atitudes dos supervisores em suas aulas. De acordo com os resultados, tanto a ajuda dos bolsistas de iniciação à docência quanto a percepção de que outros métodos podem chamar mais atenção e diminuir as dúvidas dos estudantes levaram a que esse grupo de sujeitos buscassem outras formas de ministrar aulas de Física. Portanto, a situação proporcionada pelo programa vai ao encontro da concepção de Pinheiro (2003), ao salientar que novas ideias influenciam o modo como o sujeito vê as coisas, tornando-o capaz de mudar o jeito de ser, o comportamento, ou seja, sua atitude diante da mesma situação. 
Atribuição

A segunda categoria buscada foi a atribuição, a qual, conforme Lafortune e Saint-Pierre (1996), está relacionada à interpretação das causas dos acontecimentos, como atribuir sucesso à qualidade e à eficácia das estratégias utilizadas. Assim, agruparam-se, nesta categoria, trechos das entrevistas dos supervisores do Pibid/Física que demonstram as aprendizagens que, em sua opinião, originaram-se a partir da sua participação no programa. Sobre isso, transcreve-se a fala de E1:

Olha, eu sempre tive essa postura, apesar de que no começo eu era bem rígido e mecânico, avaliava muito essa questão de ver que o aluno sabe e não me importava com a maneira com que ele aprendia, e em cada individualidade, eu pensava no coletivo e todo mundo tem que ir bem e pronto, mas eu percebo que mudou. Com o Pibid a gente foi mudando, [...] nos últimos anos me tornei mais extrovertido. E vejo que deu certo, os alunos aprendem mais facilmente. Os bolsistas [pibidianos] que me acompanham sabem que às vezes eu chamo atenção, mas levo o trabalho a sério, extrovertido, mas, quando tem que puxar, eu cobro (E1).

Os demais supervisores pesquisados atribuem ao Pibid/Física a possibilidade de estarem em contato com outras metodologias de ensino e a melhora no desenvolvimento de suas aulas. Para esses sujeitos, como se pode perceber nos trechos das entrevistas transcritos no Quadro 3, o programa proporcionou-lhes estar em contato com outras situações que diversificaram seu fazer pedagógico na direção de um ensino que atinja individualmente todos os estudantes.

Quadro 3 - Trechos das entrevistas que demonstram a atribuição dos supervisores pesquisados às novas metodologias empregadas no seu fazer pedagógico

Na verdade, eu sempre fui muito metida, sempre gostei de fazer coisas diferentes. No entanto, sempre tive várias turmas de ensino médio e ficava limitada [...]. Com o Pibid tive a oportunidade de realizar então uma feira de ciências, mostra do conhecimento, atividades experimentais [...], fazer trabalhos assim. Claro que isso não ocorre diariamente, mas agora eu sempre busco desenvolver atividades assim. Porque cada aluno aprende de um jeito, e a gente tem que buscar coisas e atividades que atendam 
$\operatorname{todos}(\mathrm{E} 1)$.

Com o Pibid, como gosto muito da prática, seja o que for, seja eletricidade, ótica, mecânica, todos os segmentos, eu uso bastante a prática. Comecei a levar para a sala de aula muita atividade prática, pois essas sempre ajudam a individualidade de aprendizagem de cada aluno (E5).

Eu sempre tentava conversar com eles, principalmente nos primeiros períodos, falar como a Física pode ser interessante, mas não conseguia muito motivar meus alunos. Com os estudos que fizemos nos encontros aqui na universidade, fui compreendendo melhor não só os conceitos de Física, mas também a história desta ciência. Assim, ficou mais fácil de comentar com os estudantes como tu pode ver a Fisica olhando pra fora, como tu pode ver as cores, como pode medir a temperatura [...] e relacionando assim com o dia a dia. Isto é, levar eles a entenderem a Física como uma ciência que a gente vivencia diariamente, cada um vai ver o conteúdo diferente, e dando exemplos do dia a dia, do mundo lá fora, eles conseguem aprender melhor (E6).

Fonte: dados da pesquisa, 2017.

Para os professores pesquisados, participar do Pibid/Física proporcionou-lhes a vivência de novas situações e o contato com metodologias de ensino diversas, que foram responsáveis pela melhoria da qualidade de suas aulas. Nesse sentido, os resultados indicam que os professores atribuem ao programa a possibilidade de alterar a dinâmica do processo de ensinar e aprender Física. Essa ideia corrobora as concepções de Lafortune e Saint-Pierre (1996) e de Pinheiro (2003), ao afirmarem que, quando o professor considera que o talento ou até mesmo o interesse dos alunos dependem dele, deve desenvolver novas metodologias buscando superar as dificuldades de aprendizagem.

\section{Emoção}

As emoções estão relacionadas às reações afetivas que são manifestadas de diferentes maneiras, como felicidade, amor, medo, desgosto, tristeza, raiva, entre outros, sendo elas os elementos buscados para compor esta categoria. Assim, arrolaram-se nesta seção trechos das entrevistas que revelam a exteriorização de um sentimento desencadeado no decorrer da participação no Pibid/Física. 
Segundo Santos (2001), as emoções e os sentimentos desempenham um papel importante na construção de significados, porque estão relacionados aos impulsos, aos interesses e às motivações dos alunos e do professor no trabalho com o conhecimento. Essa característica foi muito evidenciada na fala dos supervisores. O principal sentimento observado no decorrer das entrevistas foi o orgulho de ser professor. Para E3, ser professor é "pensar que pra alguém tu vai fazer a diferença”. No mesmo sentido, E5 e E6 expressam que "esse trabalho de despertar do aluno, levar pra ele uma ciência e fazer com que ele se apaixone por essa ciência é empolgante” (E5); "Então quando tu consegue despertar o interesse no aluno é bem legal, [...] eles vão pesquisar e montar e ver outras coisas, buscar na internet outras coisas, dá para sentir um entusiasmo neles, e o professor também se motiva e se sente orgulhoso de ser professor” (E6).

Outro sentimento evidenciado na investigação foi a felicidade de estar participando do processo de formação de futuros colegas. Nessa perspectiva, E1 salienta: "quando eu fiz a minha graduação tive contato com a sala de aula somente no estágio. Esses pibidianos vão para a escola desde cedo, isso faz com que eles tenham mais oportunidades. Eu fico muito feliz em contar minhas experiências de professora”. O mesmo sentimento é manifestado por E6: "a felicidade é saber que tudo o que eu vivi dentro de uma sala de aula pode ser aproveitado pelos acadêmicos. Assim, é muito bom de perceber que nos buscam como apoio".

Verifica-se, no trecho da entrevista do supervisor E6, o entusiasmo em despertar nos acadêmicos interesse em seguir a profissão de docente de Física, sentimento também presente na fala de E5: “É fantástico trabalhar com pessoas que querem ser professor, eu adoro. Gosto muito, [...] o programa possibilita a troca de experiências. Então eu ajudo os bolsistas, e a minha aula enriqueceu com a presença deles. Me atualizaram”.

Em relação ao programa, o sentimento evidenciado foi o de esperança quanto à possibilidade de mudança do cenário educacional atual. Nesse sentido, E4 assim expressa: "eu vejo o Pibid como uma esperança de que 
pode dar certo, e eu acredito no ser humano [...] e que programas assim podem fazer com que os professores se formem melhor e melhorem a educação deste país". E5, por sua vez, destaca:

Cada experiência [...] cria, muda alguma coisa, e vocês mudaram, do ano passado pra cá, é claro. Agora, vou falar uma coisa, vou cuidar pra não chorar. Vocês mudaram a minha vida. Então eu tava muito desanimada no ano passado, já tava quase querendo me aposentar, e, com a vinda de vocês, parece que colocaram fogo na gasolina, parece que eu cresci, criei uma garra, uma força, uma vontade. Então é essa convivência com vocês. Então, se vocês modificaram alguma coisa? Totalmente. E eu me sinto e eu penso no caso de ano que vem não ter, eu penso "ah, eu não acredito", não é a questão da bolsa [...]. Mudou bastante, e, pessoalmente pra mim, a minha vida ficou muito mais encantadora junto com os bolsistas. Não sei se eles notam, mas eu tenho um carinho por eles, meus filhinhos e "pupilinhos", e que com certeza vão se fazendo professores, e bons professores! (E5).

Os dados obtidos nas entrevistas remetem às concepções de Lafortune e Saint-Pierre (1996), indicando que o docente que desenvolve a emoção é capaz de realizar suas atividades com maior chance de acerto. Assim, constata-se, através dos resultados, que a participação no Pibid/Física possibilitou aos supervisores desenvolver sentimentos emotivos capazes de contribuir significativamente para sua prática pedagógica.

Confiança em si mesmo

A confiança em si mesmo é um conceito relacionado à autoestima e pode ser entendida como uma crença sobre a própria competência e capacidade para alcançar determinado objetivo (FERREIRA, 2012), ou seja, 
não diz respeito às capacidades reais do sujeito, mas sim ao que ele acredita ser capaz de fazer. Durante as entrevistas, notou-se que os supervisores, ao iniciar na carreira, não se sentiam capazes de ministrar aulas sem o planejamento completo, e, muitas vezes, necessitavam de resumos da atividade a ser desenvolvida, como nos revela a fala de E1: "Quando eu comecei a lecionar, eu fazia um planejamento mais detalhado, e tal, nessa questão, às vezes até um resumo em forma de esquema pra trabalhar a parte do conteúdo, e depois uma lista de exercício e depois seguia o livro didático [...] que a escola sempre adotou".

A mesma estratégia era adotada por todos os participantes da pesquisa. No entanto, eles salientam que, a partir de certo momento, sentiram-se mais confiantes em relação ao conteúdo, deixando de lado esse planejamento detalhado, apenas organizando a aula de acordo com o rendimento dos alunos, especialmente porque, com o número de turmas em que são titulares, dedicam esse tempo de planejamento para analisar trabalhos e preparar provas.

Os pesquisados salientam, também, que, ao participar do programa, observaram a progressão da confiança em si mesmos. Para eles, além de um momento destinado exclusivamente ao planejamento das aulas, às trocas de ideias com os "pibidianos" e com a coordenação de área, bem como aos estudos, obtém-se um trabalho mais organizado e detalhado, com métodos e instrumentos diferenciados que proporcionam maior segurança no desenvolvimento das atividades. Esses elementos são evidenciados na fala de E1, que assim refere:

com o Pibid agora a gente pensa, a gente planeja, "aqui, oh, vamos começar trabalhando através de vídeos, ou vamos explorar uma parte dos conceitos então através de mapas conceituais”. [O mapa conceitual] é uma coisa que eu já tinha lido um pouco na minha formação e tinha deixado um pouquinho de lado. E também a parte experimental. Estamos sempre tentando fazer 
essa parte de reflexão com o aluno, fazer o resgate dos conhecimentos prévios, pra depois aprofundar a parte do conteúdo e depois fazer uma aula experimental, e a lista de exercícios, tudo isso nos faz sermos melhores professores $e$ desenvolvermos boas aulas (E1).

Como salienta Pinheiro (2003), além do planejamento, a confiança em si mesmo, no ensino de Ciências, influencia nos métodos do professor. Um exemplo consiste nas atividades experimentais, pois, apesar de concordar que a experimentação é importante, a maioria dos docentes resiste ao seu desenvolvimento, tendo em vista diversos motivos, dentre os quais, a falta de confiança em aplicá-las. Todos os supervisores afirmaram que, apesar de já terem utilizado as atividades experimentais em sua prática, antes de participarem do programa, pouco as empregavam. A partir das atividades planejadas, conseguiram explorá-las com mais segurança e em mais ocasiões. Sobre isso, E5 ressalta: "as atividades experimentais ficaram mais diversificadas, tanto pelos materiais quanto pela proposta de aplicação, pois, com a ajuda dos pibidianos, ficava mais viável essa aplicação”. Na mesma linha, apresenta-se a fala de E1:

Sempre procurei trabalhar a parte experimental, mas a gente sabe as dificuldades que as escolas públicas enfrentam em trabalhar [...], a parte do laboratório, mas na minha escola eu consegui resgatar nos últimos quatro anos, tanto que o laboratório antes era um depósito e agora é um dos laboratórios [...] de escola pública que mais tá equipado [...]. E trabalhei então essa parte experimental quando dá, que a gente sabe que, devido à falta de professores, a gente não consegue fazer o cronograma correto como a gente prepara, mas a gente, ultimamente, antes de ingressar no Pibid, eu seguia o livro didático e quando dava pra trabalhar a parte experimental, trabalhava essa parte, e seguia mais a parte do livro 
didático mesmo. Agora com o Pibid isso mudou, agora a gente tem essa tarde, a gente sabe que nós temos esse tempo para preparação de aula, e a parte experimental, estamos sempre tentando fazer essa parte de reflexão com o aluno, fazer o resgate dos conhecimentos prévios, pra depois aprofundar a parte do conteúdo e depois fazer uma aula experimental (E1).

Segundo Pinheiro (2003), se reconhecemos nossos avanços, nossas dificuldades e capacidades, temos mais chance de obter sucesso nas atividades propostas. Um professor que não sente confiança em si mesmo, ou seja, que pensa não ter capacidade ou competência para realizar determinada atividade, se desencoraja diante da mínima dificuldade (LAFORTUNE; SAINT-PIERRE, 1996). Assim, a confiança em si interfere no trabalho do professor desde o planejamento (FERREIRA, 2012).

Um professor que se sente incapaz nunca mudará seus métodos, pois sempre reproduzirá as mesmas metodologias, por se sentir mais confiante diante delas (PINHEIRO, 2003). Do mesmo modo, como destacam Barros e Laburú (2017), ao se sentir pouco seguro em relação a certo conteúdo, irá evitá-lo ao máximo, por julgar-se com pouca capacidade ou limitação para a execução. Pelos resultados obtidos na análise dos dados desta investigação, infere-se que a confiança na própria capacidade aumentou nos supervisores ao desenvolverem atividades no Pibid/Física.

\section{Motivação}

De acordo com Lafortune e Saint-Pierre (1996), motivação compreende um conjunto de aspirações que uma pessoa possui para atingir um objetivo ou cumprir uma atividade, correspondente a suas necessidades ou seus interesses. A motivação pode estar relacionada a ações realizadas em resposta a fatores externos, em que o sujeito busca objetivos desejáveis, ou 
pode depender da própria pessoa, sendo estimulada por fatores internos, como interesse e satisfação na atividade em si (LAFORTUNE; SAINTPIERRE, 1996; PINHEIRO, 2003). Dessa forma, agruparam-se nesta categoria fragmentos das entrevistas que demonstram elementos relacionados à motivação decorrida da participação das atividades do programa.

Nos trechos das entrevistas transcritos no Quadro 4, os supervisores demonstram que as atividades desenvolvidas pelo programa são renovadoras de autoestima e motivação em relação à profissão.

Quadro 4 - Trechos das entrevistas que demonstram elementos de motivação dos supervisores pesquisados

\begin{abstract}
No começo da profissão eu estava empolgada com a profissão, com pegar uma turma sozinha e tal, e no decorrer do caminho acabei me desmotivando pela situação que o Estado está, que não tem incentivo. No decorrer do tempo tu acaba perdendo um pouquinho do ânimo em função das condições, e além de que a gente não tem muito apoio. Aí, quando fui convidada a participar do Pibid veio uma nova motivação, veio uma renovação assim, de que se pode fazer uma coisa diferente, de que se pode mudar [...], que pode ser melhor, que pode ser bom (E2).
\end{abstract}

O Pibid é o marco, foi um marco pra mim como profissional, porque eu tava um pouco desanimada, sabe? Que você não tem um apoio. O professor de sala de aula, difícil de trabalhar, ainda mais a Fisica, cada vez a gente tava mais se sentindo mais num beco sem saida, sem apoio, sem estrutura, e o Pibid chegou, e no início eu fui bem relutante, [...] é que eu não entendia muito bem o que era, não sabia bem o que era, [...] daí eu fui meio que forçada, e cheguei lá e me deparei com outra situação. Foi pra mim, renovou muito a minha vontade de trabalhar, criei vínculos, e renovou, me deu um upgrade, me deu um estimulo muito grande. O Pibid foi muito bom [...], porque dai a gente começa a fazer projetos, aquilo tudo que eu gostaria de ter quando professora, o Pibid me forneceu. [...] aquilo te impulsiona, e isso te renova no sentido também de que tu ganha, tanto tu passa a tua experiência quanto tu recebe essa experiência mais jovem, que daí a gente já tá um pouquinho acomodada, daí vêm as ideias, então é um conjunto. Eu acho que assim, afetivamente, renova, dá uma outra energia, e tu começa a trabalhar, se envolve com os projetos, com as ideias [...], e te abre muitas portas pra estudar e se renovar (E3).

Nossa, o Pibid representa muita coisa, o Pibid tá trazendo jovens pra trabalhar junto comigo no planejamento, então o Pibid, pra mim, me permitiu fazer essa ponte entre o próprio relacionamento com os alunos e pibidianos e a questão da renovação, atualização, procurar aperfeiçoar aquilo que tu tá levando, não ficar sempre naquela aula só tradicional. Então o Pibid é muito importante. Acho que bom seria se todos os professores tivessem essa oportunidade (E4).

Fonte: dados da pesquisa, 2017.

Além disso, todos os entrevistados atribuem essa renovação e motivação à oportunidade de voltar à universidade, de conviver com 
acadêmicos em processo de formação, trocando experiências, ensinando e aprendendo ao mesmo tempo, como complementa E2:

pra profissão, ele representa uma esperança, de que venham mais professores com vontade, com dedicação, que os alunos enxerguem a Física de uma outra forma, não só como aprendiam antigamente, que era só resolução de problemas, caderno e livro [...]. Que o Pibid, na verdade ele traz uma aula diferente [...], só pelo fato de ter mais pessoas na aula, com visões diferentes daquele conteúdo, fica uma aula diferenciada, então é uma esperança de renovação, que venham coisas diferentes e que os alunos comecem a gostar mais da disciplina (E2).

Um professor motivado, de acordo com Lafortune e Saint-Pierre (1996), é capaz de encontrar meios pedagógicos que estimulem os alunos e desenvolvam atitudes positivas durante o processo de ensino-aprendizagem, tornando-os também motivados diante das atividades escolares. As autoras, concordando com muitos de seus pares, acrescentam que sem motivação não ocorre a aprendizagem, isto é, a motivação é um aspecto central quando se trata de aprender. Dessa forma, participar das atividades do Pibid/Física pode contribuir não somente para a formação inicial e continuada, mas principalmente para a melhoria da qualidade das aulas em nível médio e da compreensão dos conceitos físicos por parte dos estudantes da educação básica.

\section{Considerações finais}

O Pibid/Física visa, sobretudo, oferecer um espaço de formação inicial para acadêmicos de licenciatura no contexto de sua futura atuação profissional. No entanto, tem se mostrado um espaço capaz de mudar também a formação continuada dos supervisores, tornando-os protagonistas, enquanto participam da coformação de jovens futuros professores. Através 
da interação entre os docentes com experiência e os licenciandos, pode-se obter um ambiente cheio de confiança e motivação.

Os dados coletados nesta pesquisa demonstram que o Pibid/Física influencia a formação de elementos do domínio afetivo na relação do professor com sua profissão. Ao interpretá-los, evidenciou-se que o programa ajudou na renovação e motivação dos supervisores, aumentando seu interesse pela docência, a ponto de, ao trabalhar novas atividades e projetos, se sentirem mais animados, tanto pela presença dos pibidianos como pela oportunidade de descobrir novas estratégias didáticas. Essa motivação possibilitou-lhes refletir, buscar aprimoramento, mudar sua postura perante os estudantes de ensino básico, tentando suprimir as dificuldades existentes. Além disso, constatou-se que, ao ingressar no programa, os supervisores se sentiram mais confiantes, passaram a usar novos métodos, mais atividades experimentais em suas aulas, alterando, assim, suas atribuições e atitudes.

Por fim, a pesquisa evidenciou a dificuldade que os supervisores encontraram na execução do programa em inserir colegas nas atividades desenvolvidas. Segundo os entrevistados a falta de colaboração dos colegas de outras áreas limitou a implementação de algumas propostas. Mesmo assim, os supervisores acreditam que o Pibid/Física representa uma esperança, dando condições aos futuros professores para que saiam da graduação mais motivados, com vontade de mudar o contexto atual da profissão e capazes de promover um ensino que leve os estudantes à compreensão dos conteúdos físicos desenvolvidos nos bancos escolares de nível médio. Ainda, cabe ressaltar que os resultados indicam "inovação e aproximação" da universidade com a rede de ensino básico, contemplando os estudos dos supervisores e fortalecendo a renovação do sentimento de ser professor.

\section{Referências bibliográficas}


BARROS, M. A.; LABURÚ, C. E. O papel das crenças de autoeficácia na formação de professores de Física do Ensino Médio. Ensino e Tecnologia em Revista, Londrina, v. 1, n. 1, p.124-138, 2017.

BRASIL. Ministério da Educação. Portal. Pibid - Apresentação. Disponível em: <http://portal.mec.gov.br/pibid>. Acesso em: 31 maio 2017.

CHARLOT, B. O professor na sociedade contemporânea: um trabalhador da contradição. Revista da Faeeba: Educação e Contemporaneidade, Salvador, v. 17, n. 30, p. 17-31, 2008.

DAMÁSIO, A. O erro de Descartes: emoção razão e o cérebro humano. São Paulo: Companhia das Letras, 1996.

. O mistério da consciência: do corpo e das emoções do conhecimento em si. São Paulo: Companhia das Letras, 2000.

DARROZ, L. M. Os impactos do Programa Institucional de Bolsa de Iniciação à Docência (Pibid/Capes) na formação do professor de Física do Rio Grande do Sul. Tese de doutorado em Educação em Ciências: Química da Vida e Saúde, Instituto de Ciências Básicas da Saúde - Universidade Federal do Rio Grande do Sul, Porto Alegre, 2016.

; WANNMACHER, C. M. D. Aprendizagem docente no âmbito do Programa Institucional de Bolsa de Iniciação à Docência - Física: o que dizem os supervisores. Imagens da Educação, v. 6, n. 1, p. 38-49, 2016.

FERREIRA, G. K. Investigando a influência do domínio afetivo em atividades didáticas de resolução de problemas de Física no ensino médio. Dissertação de mestrado em Educação Científica e Tecnológica - Universidade Federal de Santa Catarina, Florianópolis, 2012.

GIL, A. C. Métodos e técnicas de pesquisa social. 4 ed. São Paulo: Atlas, 1994. Como elaborar projetos de pesquisa. 4. ed. São Paulo: Atlas, 2002.

JESUS, S. N. Desmotivação e crise de identidade na profissão docente. Katálysis, Florianópolis, v. 7, n. 2, p. 192-202, jul./dez. 2004.

LA FORTUNE, L.; SAINT-PIERRE, L. A afectividade e a metacognição na sala de aula. Tradução de Joana Chaves. Lisboa: Instituto Piaget, 1996.

LAPO, F. R.; BUENO, B. O. Professores, desencanto com a profissão e abandono do magistério. Cadernos de Pesquisa, n. 118, p. 65-88, 2003.

LUDKE, M.; ANDRÉ, M. E. D. A. Pesquisa em educação: abordagens qualitativas. São Paulo: EPU, 1986.

MORAES, R. Uma tempestade de luz: a compreensão possibilitada pela análise textual discursiva. Ciência \& Educação, Porto Alegre, v. 9, n. 2, p. 191-211, 2003. 
; GALIAZZI, M. C. Análise textual discursiva: processo reconstrutivo de múltiplas faces. Ciência \& Educação, v. 12, n. 1, p. 117-128, 2006.

; Análise textual discursiva. Ijuí: Ed. Unijuí, 2011.

PINHEIRO, T. F. Sentimento de realidade, afetividade e cognição no ensino de ciências. Tese de doutorado em Educação: Ensino de Ciências Naturais - Centro de Ciências da Educação, Universidade Federal de Santa Catarina, Florianópolis, 2003.

REEVE, J. Motivação \& emoção. Tradução de Luís Antônio Fajardo Pontes e Stella Machado. 4. ed. Rio de Janeiro: LTC, 2015.

ROSA, C. T. W. Metacognição no Ensino de Física: da concepção à aplicação. Passo Fundo: UPF Editora, 2014.

SANTOS, F. M. T. Do ensino de Ciências como mudança conceitual à fronteira de uma abordagem afetiva. Dissertação de mestrado em Educação: Educação e Ciências - Centro de Ciências da Educação, Universidade Federal de Santa Catarina, Florianópolis, 1996.

Múltiplas dimensões das interações em sala de aula. Tese de doutorado em Educação - Universidade Federal de Minas Gerais, Belo Horizonte, Minas Gerais, 2001.

Recebido em junho de 2018. Aprovado em dezembro de 2018. 